\title{
A Comparative Modeling and Multi- Objective Optimization in Wire EDM Process on H21 Tool Steel Using Intelligent Hybrid Approach
}

\author{
Bikash Choudhuri*, Ruma Sen, Subrata Kumar Ghosh, S. C. Saha \\ Mechanical Engineering Department \\ National Institute of Technology, Agartala, India, 799046 \\ *Email: choudhurib@gmail.com,
}

\begin{abstract}
H21 steel is one of the hot work tool steel, which exhibits superior red hardness, high mechanical strength and difficult-to-machine. Wire electrical discharge machining (WEDM) always demands high-speed and high-precision machining to fulfill productivity and accuracy of machining hard materials. Cutting speed determines the productivity of machining and the width of kerf determines the tolerance of finished product. Two methodologies viz. response surface method (RSM) and artificial neural network (ANN) are compared for their modeling, sensitivity analysis and optimization abilities. The predictability of ANN model is better than RSM which indicating the advantage of ANN in mapping the nonlinear behavior of the system. Finally, the ANN fitness function is integrated with particle swarm optimization (PSO) algorithm to optimize the process parameters of the WEDM process.
\end{abstract}

Keywords: WEDM, H21 tool steel, RSM, ANN, PSO.

\section{INTRODUCTION:}

Hot work steels are mostly used in die making industries due to their capability to retain hardness at elevated temperature, with sufficient strength and toughness [1]. AISI H21 grade steel is a hot working tool steel, which contains Tungsten, chromium and vanadium, with the characteristics of high harden-ability, excellent toughness, red hardness, high compressive strength and wear resistance at elevated temperatures. It is widely used in making tool, dies, extrusion mandrels, moulds, cores, hot work punches etc. Machining of such steel in conventional machine is very tough. So, when accuracy and productivity both are considerable factors, WEDM will be the best alternative for machining such steel. Wire electrical discharge machining is extensively used in machining of any conductive materials to realize productivity and improved accuracy for manufacturing [2]. Machining with this machine is treated as a challenging task because improvement of more than one machining performance measures like metal removal rate, surface roughness, and kerf width is required to obtain a precision work [3]. In WEDM, an ionized channel between the nearest points of the work-piece and the wire electrode is created by the applied voltage. Here, an ignition delay is needed to evaporate the eroded particles in the gap. It is known that the energy in the spark gap increases with increased pulse current, pulse on-time and voltage. The depth and diameter of the WEDM craters are determined by the factors like energy in the spark gap, thermal conductivity, melting temperature, heat of fusion, thermal diffusivity and other thermo-physical properties of the electrode [4].

Very few literatures have been found to have cast the glances on machining of H21 tool steel or similar material in WEDM. Narcis et al. [5] carried out certain experiments in H13 tool steel by varying EDM parameters using different geometries of copper electrodes. Material removal rate, surface roughness, different dimensional and geometrical micro-accuracies are analyzed through statistical methods. Ramakrishnan et al. [6] narrated the effect of various WEDM parameters such as pulse on time, pulse off time, wire tension, wire feed speed and ignition current intensity on heat-treated tool steel considering MRR, surface roughness and wire wear ratio as responses. Ikramet et al. [7] reported the effect and optimization of eight control factors on MRR, surface roughness and kerf in WEDM process for D2 tool steel. It has been confirmed that pulse on-time is the most significant factor affecting the surface roughness, kerf and material removal rate. When pulse duration is high, the intensity of discharge becomes high, resulting the high cutting speed and poor surface finish and wider the width of kerf $[8,9]$.

Selection of the optimal machine settings plays an important role to achieve high quality and performance in any machining process. As WEDM is an expensive and widely used process, optimization of the WEDM process parameters is very essential to achieving good quality and high productivity [10]. It can be concluded 
that EDM/WEDM are random and stochastic in nature so there are several number of variables that control the performance of WEDM process [11, 12]. Cutting speed (CS) determine the economy and productivity whereas kerf width $(\mathrm{KW})$ denote the degrees of precision. In previous literatures, very few attempts were made to improve the quality and productivity of wire EDM process. In this present article, both CS \& KW are taken into consideration so that overall accuracy and performance of machining get improved. It is very difficult to map all the conflicting objectives and optimize the process parameters. The main goal of this study is to maximize the cutting speed and minimize the Kerf. To achieve the abovementioned objectives, RSM and artificial neural network are used to map the input/output relationships with the help of the experimental data. Then best fitted model is hybridized with particle swarm optimization (PSO) to search the best combination of WEDM parameters that will fulfill both objectives at a time.

\section{EXPERIMENTAL DETAILS}

During this study, a series of experiments were conducted in $\mathrm{H} 21$ tool steel by using ELEKTRA SPRINTCUT CNC wire electrical discharge machine. Soft brass wire $(0.25 \mathrm{~mm}$ diameter $)$ has been used as tool electrode. During the experimentation, deionized water is used as a dielectric fluid to submerge the work electrode. Wire running speed is $4.0 \mathrm{~m} / \mathrm{min}$. Flushing pressure is $10.0 \mathrm{~L} / \mathrm{min}$. The specification of work material is shown below in Table 1. The basic properties of $\mathrm{H} 21$ tool steel that makes it suitable for wire electric discharge machining is shown in Table 2.

In the present study, the experiments are designed on the basis of the central composite design (CCD) technique. The process variables and their levels are shown in Table 3. The full factorial CCD is designed with 47 combinations of the factors at five levels and composed of 32 cube points, 5 center points in cube, and 10 axial points as shown in Table 4 .

TABLE I Chemical composition of $\mathrm{H} 21$ tool steel

\begin{tabular}{lllllllllll}
\hline Elements & $\mathrm{C}$ & $\mathrm{Cr}$ & $\mathrm{Mn}$ & $\mathrm{Ni}$ & $\mathrm{P}$ & $\mathrm{S}$ & $\mathrm{Si}$ & $\mathrm{W}$ & $\mathrm{V}$ & $\mathrm{Fe}$ \\
\hline Contribution (\%) & 0.31 & 3.18 & 0.23 & 0.14 & 0.021 & 0.005 & 0.16 & 8.52 & 0.33 & Balance \\
\hline
\end{tabular}

TABLE 2 Basic physical properties of $\mathrm{H} 21$ tool steel.

\begin{tabular}{ll}
\hline \multicolumn{2}{c}{ Properties of $\mathrm{H} 21$} \\
\hline Density & $8.28 \mathrm{G} / \mathrm{M} 3$ \\
Melting Point & $1423^{\circ} \mathrm{C}$ \\
Thermal Conductivity & $27 \mathrm{~W} / \mathrm{M} / \mathrm{K}$ \\
Electrical Resistivity & $0.52 \mu \Omega \mathrm{m}$ \\
Specific Heat Capacity & $460 \mathrm{~J} / \mathrm{Kg}-\mathrm{K}$ \\
Hardness & Around $50 \mathrm{HRC}$ \\
\hline
\end{tabular}

TABLE 3 WEDM parameters used in the experimentation.

\begin{tabular}{lccccccc}
\hline \multicolumn{1}{c}{ parameters } & Symbol & Unit & \multicolumn{5}{c}{ Level } \\
\cline { 3 - 7 } & & & -2 & -1 & 0 & 1 & 2 \\
\hline Pulse on time & $\mathrm{T}_{\text {on }}$ & $* \mathrm{mu} / \mu \mathrm{sec}$ & $105 / 0.35$ & $110 / 0.6$ & $115 / 0.85$ & $120 / 1.1$ & $125 / 1.35$ \\
Pulse off time & $\mathrm{T}_{\text {off }}$ & $\mathrm{mu} / \mu \mathrm{sec}$ & $30 / 9.5$ & $37 / 12.5$ & $44 / 17$ & $51 / 28$ & $58 / 46$ \\
Current & $\mathrm{IP}$ & $\mathrm{A}$ & 140 & 160 & 180 & 200 & 220 \\
Servo voltage & $\mathrm{SV}$ & $\mathrm{V}$ & 20 & 30 & 40 & 50 & 60 \\
Wire Tension & $\mathrm{WT}$ & $\mathrm{mu} / \mathrm{kg}$ & $2 / 0.4$ & $4 / 0.5$ & $6 / 0.7$ & $8 / 1.0$ & $10 / 1.4$ \\
& & & & & & $*$ mu $=$ machine unit \\
\hline
\end{tabular}

TABLE 4 Central composite design of experiments and results

\begin{tabular}{cccccccc}
\hline Run & $\mathrm{T}_{\text {on }}$ & $\mathrm{T}_{\text {off }}$ & Ip & SV & WT & CS $(\mathrm{m} / \mathrm{min})$ & KW $(\mu \mathrm{m})$ \\
\hline 1 & 0.6 & 12.5 & 160 & 30 & 0.5 & 1.228 & 326.2 \\
2 & 1.1 & 12.5 & 160 & 30 & 0.5 & 1.978 & 346.4 \\
3 & 0.6 & 28 & 160 & 30 & 0.5 & 0.840 & 322.9 \\
4 & 1.1 & 28 & 160 & 30 & 0.5 & 1.667 & 336.7 \\
5 & 0.6 & 12.5 & 200 & 30 & 0.5 & 1.248 & 326 \\
6 & 1.1 & 12.5 & 200 & 30 & 0.5 & 1.978 & 345.2 \\
7 & 0.6 & 28 & 200 & 30 & 0.5 & 0.893 & 329.7 \\
8 & 1.1 & 28 & 200 & 30 & 0.5 & 1.668 & 343.9 \\
9 & 0.6 & 12.5 & 160 & 50 & 0.5 & 1.284 & 337 \\
10 & 1.1 & 12.5 & 160 & 50 & 0.5 & 1.987 & 353 \\
11 & 0.6 & 28 & 160 & 50 & 0.5 & 0.683 & 339.9 \\
12 & 1.1 & 28 & 160 & 50 & 0.5 & 1.345 & 341.1 \\
13 & 0.6 & 12.5 & 200 & 50 & 0.5 & 1.259 & 339.3 \\
14 & 1.1 & 12.5 & 200 & 50 & 0.5 & 1.952 & 348.1 \\
15 & 0.6 & 28 & 200 & 50 & 0.5 & 0.709 & 339.1 \\
\hline
\end{tabular}




\begin{tabular}{|c|c|c|c|c|c|c|c|}
\hline 16 & 1.1 & 28 & 200 & 50 & 0.5 & 1.389 & 344.9 \\
\hline 17 & 0.6 & 12.5 & 160 & 30 & 1 & 1.424 & 316.5 \\
\hline 18 & 1.1 & 12.5 & 160 & 30 & 1 & 1.978 & 338.1 \\
\hline 19 & 0.6 & 28 & 160 & 30 & 1 & 0.893 & 320.3 \\
\hline 20 & 1.1 & 28 & 160 & 30 & 1 & 1.856 & 345 \\
\hline 21 & 0.6 & 12.5 & 200 & 30 & 1 & 1.619 & 322.6 \\
\hline 22 & 1.1 & 12.5 & 200 & 30 & 1 & 2.000 & 337.7 \\
\hline 23 & 0.6 & 28 & 200 & 30 & 1 & 0.962 & 322.7 \\
\hline 24 & 1.1 & 28 & 200 & 30 & 1 & 1.875 & 341.8 \\
\hline 25 & 0.6 & 12.5 & 160 & 50 & 1 & 1.362 & 325.4 \\
\hline 26 & 1.1 & 12.5 & 160 & 50 & 1 & 1.996 & 345.9 \\
\hline 27 & 0.6 & 28 & 160 & 50 & 1 & 0.680 & 326.7 \\
\hline 28 & 1.1 & 28 & 160 & 50 & 1 & 1.308 & 343.4 \\
\hline 29 & 0.6 & 12.5 & 200 & 50 & 1 & 1.366 & 323.9 \\
\hline 30 & 1.1 & 12.5 & 200 & 50 & 1 & 2.000 & 348.7 \\
\hline 31 & 0.6 & 28 & 200 & 50 & 1 & 0.669 & 325.8 \\
\hline 32 & 1.1 & 28 & 200 & 50 & 1 & 1.402 & 340.8 \\
\hline 33 & 0.35 & 17 & 180 & 40 & 0.7 & 0.674 & 317.8 \\
\hline 34 & 1.35 & 17 & 180 & 40 & 0.7 & 1.944 & 357 \\
\hline 35 & 0.85 & 9.5 & 180 & 40 & 0.7 & 1.931 & 339.6 \\
\hline 36 & 0.85 & 46 & 180 & 40 & 0.7 & 0.787 & 334.9 \\
\hline 37 & 0.85 & 17 & 140 & 40 & 0.7 & 1.571 & 326.3 \\
\hline 38 & 0.85 & 17 & 220 & 40 & 0.7 & 1.721 & 329.2 \\
\hline 39 & 0.85 & 17 & 180 & 20 & 0.7 & 1.935 & 329.2 \\
\hline 40 & 0.85 & 17 & 180 & 60 & 0.7 & 1.333 & 346.5 \\
\hline 41 & 0.85 & 17 & 180 & 40 & 0.4 & 1.711 & 339.6 \\
\hline 42 & 0.85 & 17 & 180 & 40 & 1.4 & 1.833 & 326.1 \\
\hline 43 & 0.85 & 17 & 180 & 40 & 0.7 & 1.860 & 337.3 \\
\hline 44 & 0.85 & 17 & 180 & 40 & 0.7 & 1.741 & 339 \\
\hline 45 & 0.85 & 17 & 180 & 40 & 0.7 & 1.718 & 338.5 \\
\hline 46 & 0.85 & 17 & 180 & 40 & 0.7 & 1.812 & 336 \\
\hline 47 & 0.85 & 17 & 180 & 40 & 0.7 & 1.757 & 336.9 \\
\hline
\end{tabular}

\section{A. Machining Performance Evaluation}

Cutting speed has been used to evaluate machining performance. Cutting speed, under each cutting condition is calculated by dividing 'length of cut of each cut' by 'the time of machining'. The unit of cutting speed is $\mathrm{mm} / \mathrm{min}$.

Kerf width determines dimensional accuracy of the machined components. Lower the kerf width, higher the dimensional accuracy [9]. The kerf of the workpieces after machining is measured using an Optical microscope. For each cut, total 100 kerf width measurements have been taken at different positions along the length of each cut and finally, the average values are presented in Table 4. Fig. 1(a) depicts the schematic view and Fig. 1(b) depicts the microscopic view of kerf width after wire electro-discharge machining. The unit of kerf width is $\mu \mathrm{m}$.

(a)

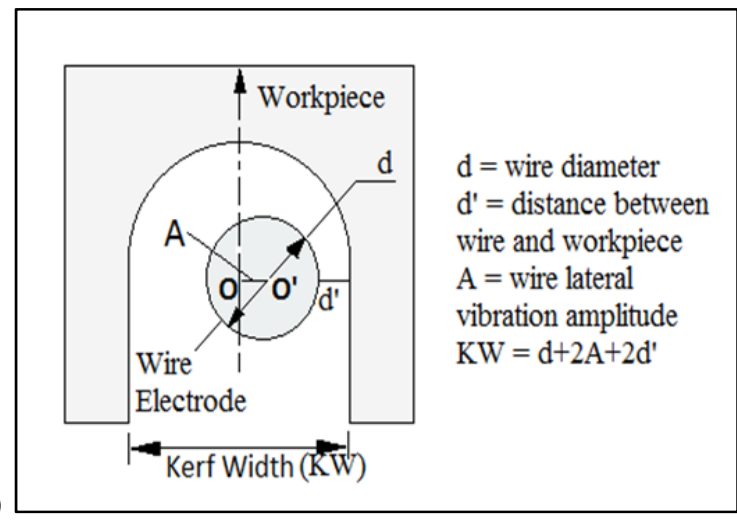

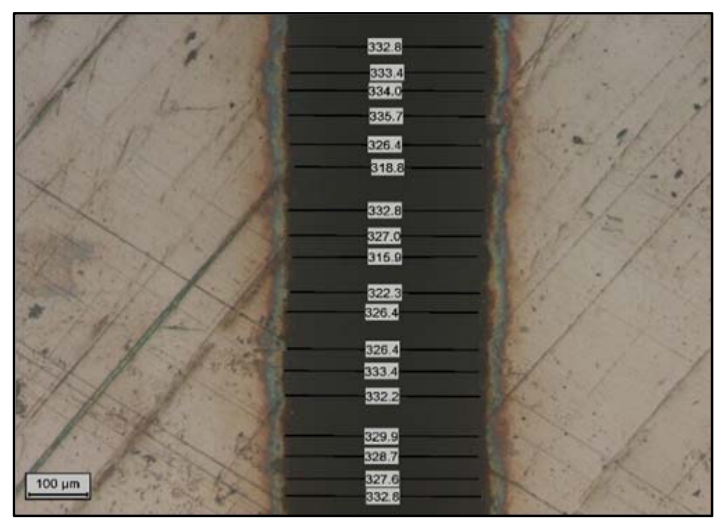

Fig. 1. (a) Schematic view (b) Microscopic view of the kerf width machined by WEDM

\section{PREDICTIVE MODELING AND OPTIMIZATION}

The same design of experiment (as shown in Table 4) is used to build the RSM and ANN model. Prediction ability of both the models is checked through statistical methods. PSO is used to provide the best parametric combination. 


\section{A. Construction of Response Surface Methodology (RSM) Model}

Response surface methodology (RSM) includes mathematical and statistical techniques for modeling and optimization of response variables which are influenced by several process variables [13]. Before applying RSM, it is required to check proper selection of process parameters and their ranges from previous studies and trial experiments for proper experimental design. Central composite design (CCD) for five independent variables at five levels is used to plan experimental design. The behavior of the system is explained by the following second order polynomial model presented in Eq. 1, on which the fitted dependent variable is viewed as a surface [14].

$Y=b_{0}+\sum_{i=1}^{k} b_{i} X_{i n}+\sum_{i=1}^{k} b_{i i} X_{i n}^{2}+\sum_{j>i}^{k} b_{i j} X_{i n} X_{j n}$

Where $\mathrm{Y}$ is the response (CS, KW); $b_{0}, b_{i}, b_{i i}, b_{i j}$ are the co-efficients; $X_{i n}\left(\mathrm{~T}_{\mathrm{on}}, \mathrm{T}_{\text {off }}, \mathrm{IP}, \mathrm{SV}, \mathrm{WT}\right) ; \mathrm{n}$ is the number of experiments; $k$ is the number of factor; $X_{i n}, X_{j n}$ are the iteration numbers.

\section{B. Construction of Artificial Neural Network (ANN) Model}

Feed forward neural network is highly flexible modeling tool due to its complex and nonlinear behaviors. It has the ability to learn the mapping between input and output parameters $[8,15]$. In the networks, the neurons are interconnected by different layers namely input layer, one or more hidden layer(s) and output layer [16]. The information is received by the input layer and passes to output layer through the hidden layer(s). The strength between each connection among the neurons is scaled via weights. An extra input is appended to neurons called bias. Each neuron in hidden layer and output layer carries a transfer function. Transfer function carries the sum of weighted inputs with a bias [15]. In this study, feed forward back propagation neural network with 5 input neurons, one hidden layer (13 neurons) and 2 output neurons include CS, $\mathrm{KW}$ is used to model the process as shown in Fig. 2.

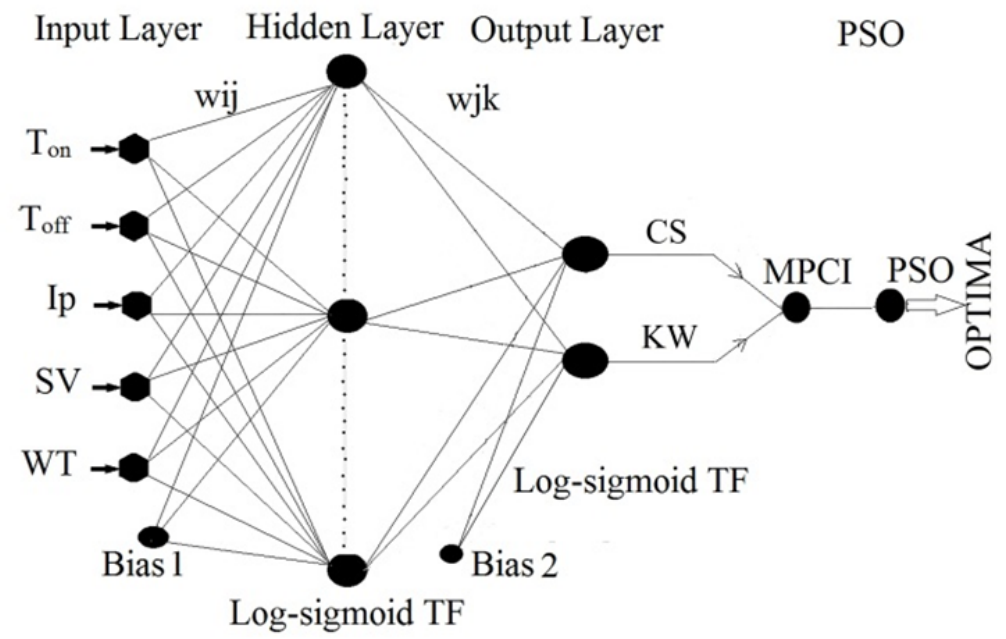

Fig. 2. Configuration of the ANN model with PSO.

In this network, each summing function collects total net input from all the neurons in proceeding layer(s). Summation function used in this study is given in Eq. (2).

$n e t_{j}=\sum_{k=0}^{n} \mathrm{x}_{i} w_{i}+b_{i} \quad j=1,2,3 \ldots \ldots$

The output $\mathrm{j}^{\text {th }}$ neuron of hidden layer is indicated as $H_{j}$

$H_{j}=f\left(\right.$ net $\left._{j}\right)$

The logistic sigmoid function of the ANN model in this study is given in Eq. (4). The function provides a curvilinear match between each layer with proceeding layers.

Where $f\left(\right.$ net $\left._{j}\right)=\frac{1}{1+e^{-n e t}}$; range $[0,1]$

The experimental data have been used to train the network. In order to make the model quickly converge, the parameters have been normalized between 0 and 1 . The logistic activation function is used in this network. Training the BP-ANN is an iterative way where errors are minimized by backward propagation through network to update weight and thresholds between two layers [17]. The following function is used to calculate error between target output $\left(\mathrm{T}_{\mathrm{pk}}\right)$ and calculation output $\left(\mathrm{O}_{\mathrm{pk}}\right)$.

$E_{p}=\frac{1}{2 p} \sum_{p} \sum_{k}\left(T_{p k}-O_{p k}\right)^{2}$ 


\section{Assessing the Quality of Model}

The best configuration for the smart system is normally determined based on the minimum value of MSE and maximum magnitude of $\mathrm{R}^{2}$. The following statistics are used to assess the quality of RSM and ANN as well as comparing the adequacy of the models and data sets.

$R^{2}=1-\frac{\sum_{\mathrm{i}=1}^{\mathrm{n}}\left(\mathrm{Y}_{\mathrm{i}, \mathrm{Exp}}-\mathrm{Y}_{\mathrm{i}, \mathrm{Pred}}\right)^{2}}{\sum_{\mathrm{i}=1}^{\mathrm{n}}\left(\mathrm{Y}_{\mathrm{Exp}}-\mathrm{Y}\right)}$

Adj. $R^{2}=1-\frac{\left(1-R^{2}\right)(n-1)}{(n-m)}$

$M S E=\frac{1}{n} \sum_{i=1}^{n}\left(\mathrm{Y}_{\mathrm{i}, \mathrm{Exp}}-\mathrm{Y}_{\mathrm{i}, \mathrm{Pred}}\right)^{2}$

The root mean square error (RMSE) is identified through the learning process is defined as follows:

$R M S E=\sqrt{\frac{1}{n} \sum_{i=1}^{n}\left(\mathrm{Y}_{\mathrm{i}, \mathrm{Exp}}-\mathrm{Y}_{\mathrm{i}, \mathrm{Pred}}\right)^{2}}$

Where, $Y_{\text {Exp }}$ and $Y_{\text {pred }}$ represent the experimental value and the prediction value of $i_{\text {th }}$ sample for performance evaluation respectively and $n$ is the total number of samples used in validation set. MSE is the average of the prediction error squares, it can evaluate the deviation of the predicted values of the neural network. The smaller of MSE value, the better prediction of the model.

\section{Particle Swarm Optimization}

Particle Swarm Optimization (PSO) is a stochastic population-based evolutionary computation technique which is inspired by the social behavior of bird flocking or fish schooling or swarm of insects [14, 18]. The system is initialized with a population of random solution and then it searches the optima through updating generation [19]. In every iteration, each particle is updated and stores two best values. The first value is the personal best solution in terms of fitness achieved so far called 'p-best'. Another best value which leads to best solution among all the particles of the population is called as global best (g-best). This velocity and position of each particle are updated for the next fitness evaluation by accelerating each particle towards the p-best and gbest. Following formula is used to generate the new swarm particles with improved characteristics [20] -

$V_{i}^{t+1}=w^{t} V_{i}^{t}+C_{1} r_{1}\left(p_{\text {best }}^{t}-X_{i}^{t}\right)+C_{2} r_{2}\left(g_{\text {best }}^{t}-X_{i}^{t}\right) \quad \mathrm{i}=1,2,3, \ldots \ldots \mathrm{t}$

$X_{i}^{t+1}=X_{i}^{t}+V_{i}^{t+1}$

$V_{i}^{t}$ and $V_{i}^{t+1}$ are the velocities of particle $\mathrm{i}$ at iteration $\mathrm{t}$ and $\mathrm{t}+1$.

$X_{i}^{t}$ and $X_{i}^{t+1}$ are the positions of particle $\mathrm{i}$ at iteration $\mathrm{t}$ and $\mathrm{t}+1$

$w$ is the inertia weight; $C_{1}$ and $C_{2}$ are cognitive (individual) and social (group) learning rate. $r_{1}$ and $r_{2}$ are random numbers uniformly distributed within the range of 0 and 1 .

$p_{\text {best }}^{t}$ and $g_{\text {best }}^{t}$ are the best positions in the current swarm and $i^{\text {th }}$ particle over generation $t$ respectively. Then the evaluated objective function corresponding to the particles is $f\left[X_{1}(i)\right], f\left[X_{2}(i)\right]$.... $f\left[X_{n}(i)\right]$. The iteration process is continued until all particles are converged to the same optima [17].

A. Modeling Result and Analysis

\section{RESULT AND DISCUSSION}

1) Predictive Modeling with RSM:

The experimental results are analyzed by using analysis of variance. These are presented in Table 5 and 6 . The fit summary suggests that the RSM quadratic model is statistically significant for analysis of CS and KW. The $R^{2}$ value $(0.9871,0.9710)$ and the Adjusted $R^{2}$ value $(0.9820,0.9596)$ and predicted $R^{2}$ value $(0.9672$, 0.9366) for the model term CS, KW are indications of good general ability and accuracy of polynomial model. The P-values are used as a tool to check the significance of each of the coefficients. The Model P-value of CS, and $\mathrm{KW}$ is less than 0.0001 which indicates that the model terms are statistically significant. F-value and percentage of contribution help to find significant factors and their respective ranks. Most non-significant model terms are eliminated by manual elimination of keeping alpha out 0.05 (i.e. confidence level 95\%). The lack of fit value in Table 5, and 6 is non-significant which is desired. Fig. 3 (a) and (b) shows the comparison of experimental and predicted CS and KW respectively. 
TABLE 5 ANOVA table for cutting speed

\begin{tabular}{lcccccc}
\hline Source & Df & Seq SS & Contribution (\%) & Adj MS & F-Value & P- Value \\
\hline Model & 11 & 8.802 & 97.17 & 0.8 & 109.33 & $0.000^{*}$ \\
$\mathrm{~T}_{\text {on }}(\mathrm{A})$ & 1 & 4.692 & 51.80 & 2.434 & 332.54 & $0.000^{*}$ \\
$\mathrm{~T}_{\text {off }}(\mathrm{B})$ & 1 & 2.978 & 32.88 & 3.012 & 411.53 & $0.000^{*}$ \\
$\mathrm{Ip}(\mathrm{C})$ & 1 & 0.012 & 0.13 & 0.012 & 1.58 & 0.217 \\
$\mathrm{SV}(\mathrm{D})$ & 1 & 0.365 & 4.03 & 0.422 & 57.68 & $0.000^{*}$ \\
$\mathrm{WT}(\mathrm{E})$ & 1 & 0.07 & 0.77 & 0.06 & 8.20 & $0.007^{*}$ \\
$\mathrm{~A}^{2}$ & 1 & 0.418 & 4.62 & 0.454 & 62.06 & $0.000^{*}$ \\
$\mathrm{C}^{2}$ & 1 & 0.04 & 0.44 & 0.046 & 6.33 & $0.017^{*}$ \\
$\mathrm{D}^{2}$ & 1 & 0.054 & 0.59 & 0.054 & 7.33 & $0.010^{*}$ \\
$\mathrm{AB}$ & 1 & 0.036 & 0.39 & 0.036 & 4.86 & $0.034^{*}$ \\
$\mathrm{BD}$ & 1 & 0.113 & 1.25 & 0.112 & 15.24 & $0.000^{*}$ \\
Error & 35 & 0.256 & 2.83 & 0.007 & & \\
Lack-of-Fit & 31 & 0.243 & 2.68 & 0.008 & 2.36 & 0.210 \\
Pure Error & 4 & 0.013 & 0.15 & 0.003 & & $*$ significant
\end{tabular}

TABLE 6 ANOVA table for kerf width

\begin{tabular}{lcccccc}
\hline \multicolumn{1}{c}{ Source } & DF & Seq SS & Contribution (\%) & Adj MS & F-Value & P-Value \\
\hline Model & 12 & 4093.40 & 94.23 & 341.116 & 46.25 & $0.000^{*}$ \\
$\mathrm{~T}_{\text {on }}(\mathrm{A})$ & 1 & 2809.88 & 64.68 & 100.287 & 13.60 & $0.001^{*}$ \\
$\mathrm{~T}_{\text {off }}(\mathrm{B})$ & 1 & 9.58 & 0.22 & 34.610 & 4.69 & $0.037^{*}$ \\
$\mathrm{Ip}(\mathrm{C})$ & 1 & 11.81 & 0.27 & 11.811 & 1.60 & 0.214 \\
$\mathrm{SV}(\mathrm{D})$ & 1 & 462.21 & 10.64 & 28.828 & 3.91 & 0.056 \\
$\mathrm{WT}(\mathrm{E})$ & 1 & 380.89 & 8.77 & 70.562 & 9.57 & $0.004^{*}$ \\
$\mathrm{C}^{2}$ & 1 & 136.14 & 3.13 & 138.878 & 18.83 & $0.000^{*}$ \\
$\mathrm{~A} \times \mathrm{B}$ & 1 & 49.90 & 1.15 & 52.232 & 7.08 & $0.012^{*}$ \\
$\mathrm{~A} \times \mathrm{D}$ & 1 & 47.13 & 1.08 & 47.132 & 6.39 & $0.016^{*}$ \\
$\mathrm{~A} \times \mathrm{E}$ & 1 & 100.07 & 2.30 & 100.069 & 13.57 & $0.001^{*}$ \\
$\mathrm{~B} \times \mathrm{D}$ & 1 & 22.30 & 0.51 & 21.472 & 2.91 & 0.097 \\
$\mathrm{~B} \times \mathrm{E}$ & 1 & 34.62 & 0.80 & 34.618 & 4.69 & $0.037^{*}$ \\
$\mathrm{D} \times \mathrm{E}$ & 1 & 28.87 & 0.66 & 28.870 & 3.91 & 0.056 \\
Error & 34 & 250.76 & 5.77 & 7.375 & & \\
Lack-of-Fit & 30 & 244.53 & 5.63 & 8.151 & 5.23 & 0.059 \\
Pure Error & 4 & 6.23 & 0.14 & 1.558 & & *significant \\
\hline
\end{tabular}

(a)

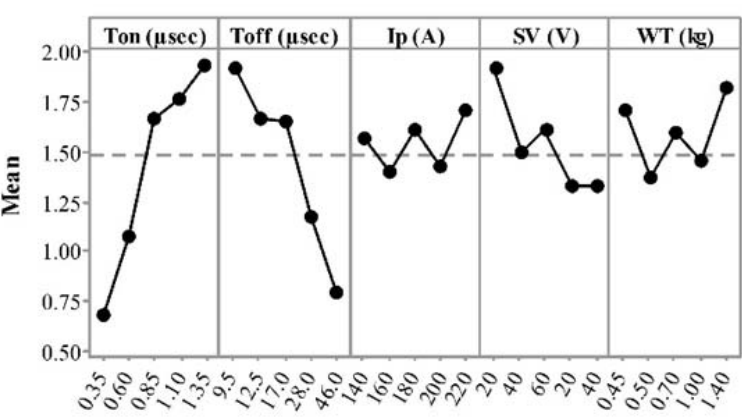

(b) Main Effects Plot for Kerf width $(\mu \mathrm{m}) \quad$ Data Means

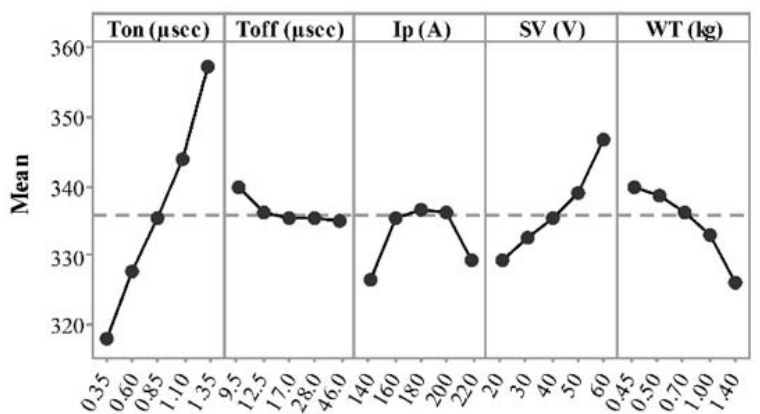

Fig. 3. Effect plots for (a) cutting speed, (b) kerf width.

The control parameters $\mathrm{T}_{\text {on }}$ and $\mathrm{T}_{\text {off }}$ on CS are found to be statistically more significant than other by contributing $51.80 \%$ and $32.88 \%$ of total contribution. At high pulse on time, pulse current is applied for long time and the plasma channel becomes denser and wider. At shorter $\mathrm{T}_{\text {off }}$, more numbers of sparks strike on the surface which may cause higher cutting speed. It is also observed from the Fig. 3 (a) and Table 5 that the cutting speed varies with the variation of servo voltage, while it remains almost constant for variation of current and wire tension. So cutting speed can be improving by taking higher value of pulse on time and lower value of pulse off time and servo gap voltage. After eliminating the non-significant terms, the final equation obtained for cutting speed is given as follows:

Cutting speed $(\mathrm{mm} / \mathrm{min})=-4.70+4.406 \times \mathrm{T}_{\text {on }}-0.0171 \times \mathrm{T}_{\text {off }}+0.0364 \times \mathrm{IP}+0.0475 \times \mathrm{SV}$ $+0.000606 \times \mathrm{WT}-1.981 \times \mathrm{T}_{\text {on }} \times \mathrm{T}_{\text {on }}-0.000099 \times \mathrm{IP} \times \mathrm{IP}-0.000425 \times \mathrm{SV} \times \mathrm{SV}+0.01692 \times \mathrm{T}_{\text {on }} \times \mathrm{T}_{\text {off }}-$ $0.000749 \times \mathrm{T}_{\text {off }} \times \mathrm{SV}-0.000011 \times \mathrm{SV} \times \mathrm{WT}$. 
Table 6 explains the analysis of variance (ANOVA) table of the kerf width. It is observed from Table 6 that the maximum percentage of contribution of $\mathrm{T}_{\text {on }}$ over kerf width is $64.68 \%$. Servo voltage $(10.64 \%)$ and wire tension $(8.77 \%)$ have also significant contribution over kerf width. When pulse duration is high, the intensity of energy discharge becomes high resulting the wider width of kerf. Fig. 3 (b) reveals that increase in average gap voltage also leads to increase in kerf width. Wire stability also affects the kerf width. High wire tension in wire increases the stability which in turn reduces wire vibration that subsequently results narrow kerf width. After eliminating the non-significant terms, the final model obtained for kerf width is given as follows:

Kerf width $(\mu \mathrm{m})=106.2+45.4 \times \mathrm{T}_{\text {on }}+0.475 \times \mathrm{T}_{\text {off }}+1.946 \times \mathrm{IP}+1.250 \times \mathrm{SV}-0.0307 \times \mathrm{WT}-0.00533 \times \mathrm{IP} \times$ $\mathrm{IP}-0.631 \times \mathrm{T}_{\text {on }} \times \mathrm{T}_{\text {off }}-0.498 \times \mathrm{T}_{\text {on }} \times \mathrm{SV}+0.02770 \times \mathrm{T}_{\text {on }} \times \mathrm{WT}-0.00996 \times \mathrm{T}_{\text {off }} \times \mathrm{SV}+0.000539 \times \mathrm{T}_{\text {off }} \times \mathrm{WT}-$ $0.000391 \times \mathrm{SV} \times \mathrm{WT}$.
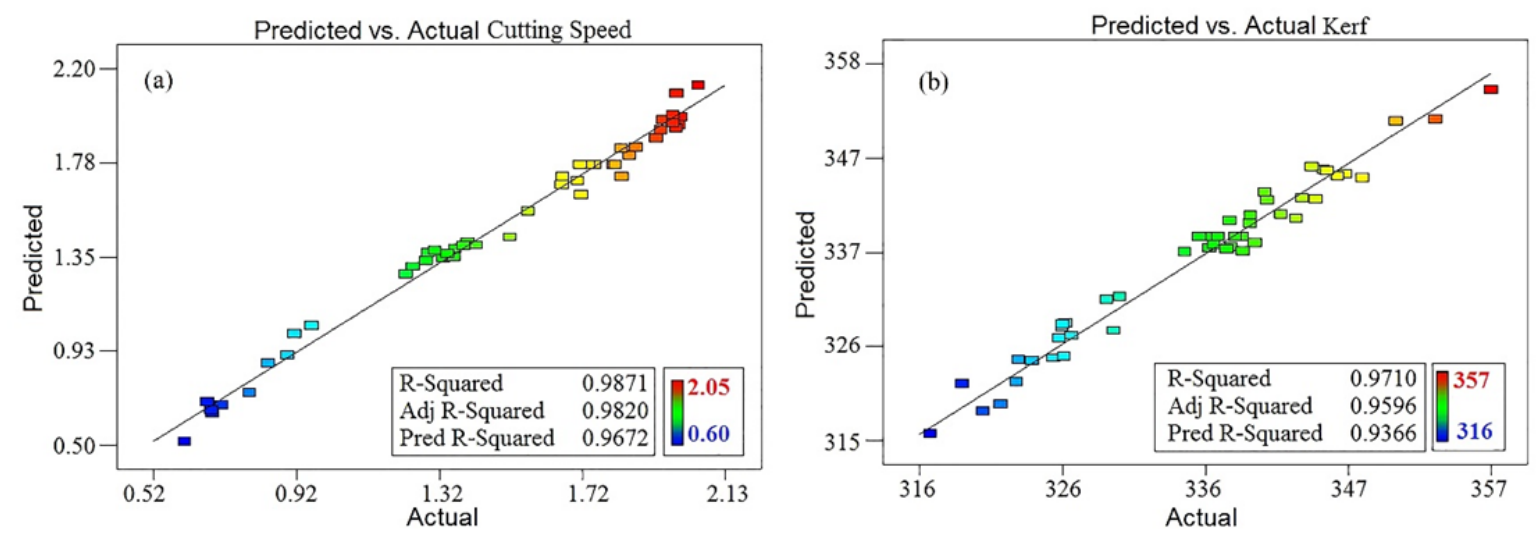

Fig. 4 Experimental (a) CS and (b) KW Vs predicted result

2) Predictive Modeling with ANN:

The CCD experimental input and output values are utilized to train the BP-ANN model (depicted in section 3.2) developed using MATLAB. The 5 inputs, 2 performances and 47 combinations of parameters are adopted as training data shown in Table 4. To test these models 7 sets of random combination experimental qualities are shown in Table 9. Initially the weights and bias are selected randomly for training data. The appropriate neural network structure for predicting all response variables was chosen by trial-and-error method. The final architecture of the neural network 5-13-2 is able to predict all responses with desired accuracy. The neural network is trained for 5,000 iterations. Network performance is evaluated using Mean Square Error (MSE) method. The errors of training datasets are computed through program and network with the smallest MSE has been considered to be optimum. The training process of the BP neural network and its performance are shown in Fig. 5. The model converges to 0.0003498 (MSE) in 5000 iterations. It is seen that the model can successfully predict the CS, and KW with RMSE $0.03312,0.9524$ respectively. The coefficients (weights) and the constants (bias) are given in Table 7 for ANN with therteen neurons. The log-sigmoidal function is used as a transfer function between input to hidden and hidden to output layer.

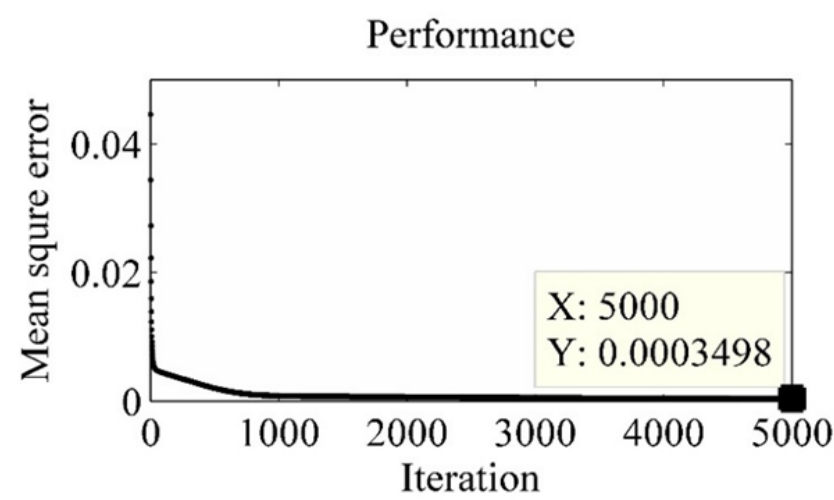

Fig. 5. Performance evaluation of neural network 
TABLE 7 The weights and bias used for training of ANN

\begin{tabular}{ccccccccc}
\hline Hidden & \multicolumn{9}{c}{ Input to Hidden (Wij) } & \multicolumn{3}{c}{ Hidden to outputs (Who) } \\
\cline { 2 - 8 } Nodes & $\mathrm{T}_{\text {on }}$ & $\mathrm{T}_{\text {off }}$ & $\mathrm{Ip}$ & $\mathrm{WT}$ & $\mathrm{SV}$ & Bias & $\mathrm{CS}$ & $\mathrm{KW}$ \\
\hline 1 & 1.9272 & 2.3112 & -2.3256 & 2.5862 & -3.0524 & 0.7074 & 0.1249 & 3.5621 \\
2 & -2.4176 & -1.2287 & -3.9967 & -0.422 & 2.027 & 0.2313 & -1.4718 & -2.8504 \\
3 & -1.2368 & -0.4318 & -1.7238 & 0.4342 & -0.6402 & 0.428 & 1.288 & 1.0819 \\
4 & -0.3948 & 2.3649 & 0.0797 & -3.0018 & 0.6613 & -1.1113 & 1.7655 & 0.2717 \\
5 & -6.3288 & -0.4971 & 0.7943 & -1.9219 & -0.8338 & 1.9139 & -3.8333 & 0.8035 \\
6 & 1.7735 & 0.0884 & 1.7377 & -4.2534 & 2.8658 & -1.0782 & 0.0013 & 2.3216 \\
7 & 1.2305 & 3.3443 & -0.2086 & 0.8668 & -0.1003 & -1.5643 & -1.6849 & 1.7026 \\
8 & -0.3254 & -1.9747 & -0.2251 & 3.1508 & -3.7506 & -0.3935 & 0.4978 & 2.5857 \\
9 & 2.9141 & -3.8993 & 2.9177 & -2.7766 & -1.3654 & 0.4618 & 0.6959 & 1.2875 \\
10 & 0.5202 & 0.3864 & -1.23 & 0.7518 & -0.3782 & -1.3611 & 0.3858 & 0.8316 \\
11 & -2.0831 & 4.6102 & 1.829 & 1.2893 & -3.9495 & 0.001 & -1.876 & -2.6124 \\
12 & -0.1452 & -1.156 & -4.0364 & -2.5554 & -0.155 & 1.21 & -2.0244 & -2.5166 \\
13 & 2.7124 & -2.8245 & 0.5085 & -3.078 & -0.9122 & 2.9238 & 3.7666 & -1.6999 \\
Bias & & & & & & & -0.9654 & -3.4753 \\
\hline
\end{tabular}

\section{3) Checking Adequacy of Model:}

The developed RSM and ANN model is well satisfied as adequacy measured by $\mathrm{R}^{2}$, adjusted $\mathrm{R}^{2}$ and RMSE explained in section 3.3 gives satisfactory results. From the equations 6 and 8 , correlation of determination $\left(\mathrm{R}^{2}\right)$ and mean square error (MSE) of CS, and KW are calculated and shown in Table 8. The comparison predicted values of CS, and KW of the WEDM of $\mathrm{H} 21$ tool steel using RSM and back-propagation neural networks along with the actual experimental values are shown in Figs. 4 (a) and (b); 6 (a) and (b) respectively. It can be seen that the ANN model is better fitted than RSM model with the experimental values. Since ANN is more accurate and more generalized model than quadratic RSM, it has better ability to find the global optimum. The best developed model is used for the optimization of process parameters of the WEDM of $\mathrm{H} 21$.
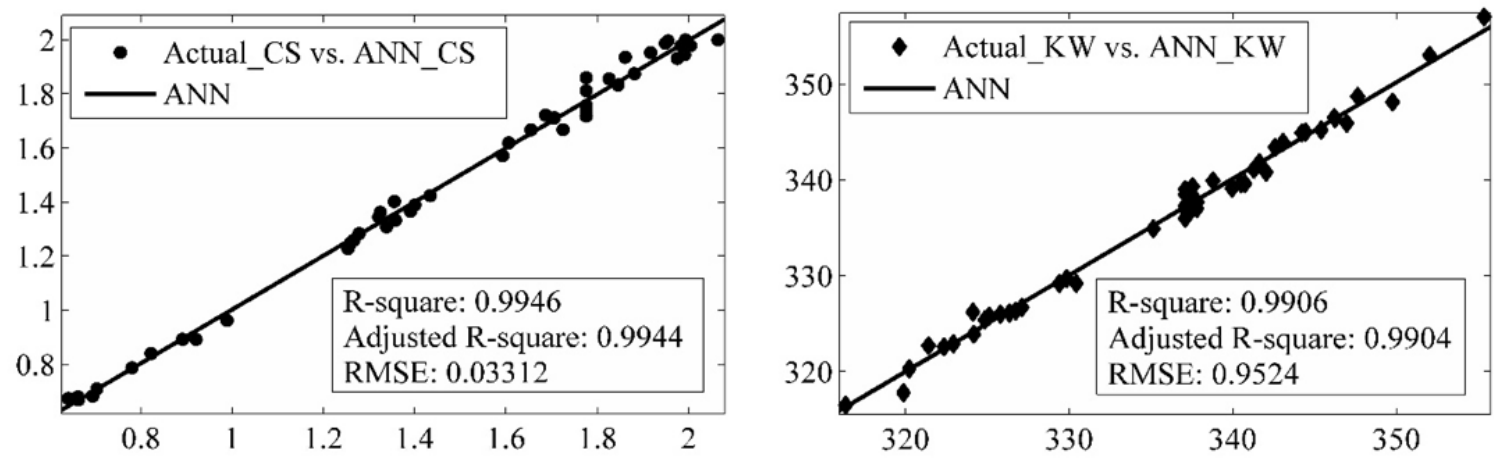

Fig. 6. Experimental Vs ANN predicted results (Training case) (a) CS, (b) kerf.

TABLE 8 Comparison of predictive capacity of RSM and ANN (training set)

\begin{tabular}{lcccc}
\hline \multirow{2}{*}{ Statistic } & \multicolumn{2}{c}{ CS } & \multicolumn{2}{c}{ KW } \\
\cline { 2 - 5 } R2 & RSM & ANN & RSM & ANN \\
\cline { 2 - 5 } Adjusted R2 & 0.9871 & 0.9946 & 0.9710 & 0.9906 \\
RMSE & 0.9820 & 0.9944 & 0.9516 & 0.9904 \\
\hline
\end{tabular}

\section{4) Testing of ANN Model}

After testing of data as shown in Table 9, it can be concluded that the neural networks appear to constitute a correct model for predicting the CS, and KW within the range of experimental conditions. The error of both responses in testing cases are very less, which proves that ANN model is successful to predict correctly all the responses. 
TABLE 9 Testing data of experimental result and neural network model

\begin{tabular}{cccccccccc}
\hline Sl & $\mathrm{T}_{\text {on }}$ & $\mathrm{T}_{\text {off }}$ & IP & SV & WT & \multicolumn{2}{c}{ CS } & \multicolumn{2}{c}{ KW } \\
\cline { 6 - 9 } No & & & & & & Exp. & ANN & Exp. & ANN \\
\hline 1 & 0.85 & 14 & 150 & 45 & 0.85 & 1.768 & 1.805 & 333.2 & 333.6 \\
2 & 0.35 & 14 & 150 & 45 & 0.85 & 0.712 & 0.689 & 315.7 & 316.4 \\
3 & 1 & 17 & 150 & 45 & 0.85 & 1.782 & 1.838 & 336.4 & 340.1 \\
4 & 0.7 & 24 & 180 & 30 & 0.60 & 1.335 & 1.338 & 331.4 & 329.4 \\
5 & 1 & 14 & 160 & 45 & 0.85 & 1.991 & 1.942 & 348.1 & 343.9 \\
6 & 1 & 14 & 200 & 45 & 0.85 & 1.987 & 1.954 & 346.8 & 340.4 \\
7 & 1 & 14 & 150 & 30 & 0.85 & 1.996 & 1.964 & 337.5 & 333.6 \\
\hline
\end{tabular}

\section{B. Optimization}

In the present work, PSO algorithm is successfully applied to solve the entire conflicting objective problem. To convert multi-response problem into single objective one i.e., multiperformance criterion index (MPCI), equal weightage is provided for both responses. The BP-ANN fitness function combined with PSO algorithm for optimization with objective of maximum MPCI and finally the respective optimized outputs are obtained separately. MATLAB programming is used for obtaining the overall objective. The results obtained from the optimization algorithm are presented in Table 10. The table presents the optimized parameters for the maximized cutting speed and minimized kerf width.

In this optimization, the critical conditions of PSO namely cognitive parameters (c1) and social parameters (c2) are taken as 2. It is also observed that 70 numbers of iteration are taken by PSO for converge to the best value as shown in Fig. 7. The initial weight and final weight are taken as 0.95 and 0.05 respectively. The population is initialized with random data. The size of the swarm is 20. The PSO initialization is based on the finding of each particle's best position in its history i.e. Pbest, If the new MPCI value is better than the best MPCI value of the previous iteration, set the current MPCI value as the new particle best fitness value, and the particle position having this particle best value is considered as particle best position (Pbest). Next the positions of best MPCI value (Gbest) within all the Pbest position has been chosen. So Gbest is the all particle's best position in their history. Gbest helps its particles to reach around the optimal position very rapidly and accurately. The particle velocity and the particle position are calculated by following equation (10) and equation (11) respectively.

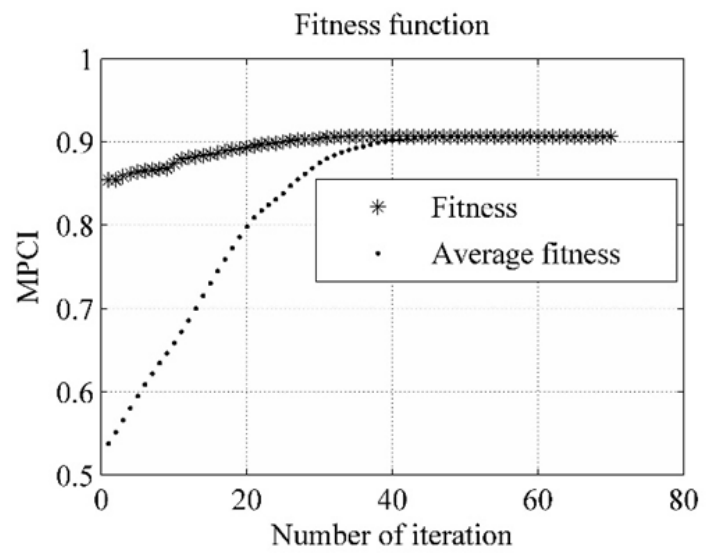

Fig. 7. Objective function convergence of PSO for the optimization of WEDM process parameter.

\section{Confirmation Tests}

The optimum combination of process parameters, according to RSM-PSO method, is also checked by confirmation experiment and the results are reported in Table 10. The error percentages are within permissible limits which confirm the adequacy of each model. Optimum parameters: Ton $=0.95 \mu \mathrm{sec}$, Toff $=9.5 \mu \mathrm{sec}, \mathrm{Ip}=$ $165 \mathrm{~A}, \mathrm{~V}=20 \mathrm{~V}, \mathrm{WT}=1.4 \mathrm{~kg}$

TABLE 10 confirmations run of optimum results.

\begin{tabular}{cccc}
\hline \multicolumn{2}{c}{ Cutting Speed $(\mathrm{mm} / \mathrm{min})$} & \multicolumn{2}{c}{ Kerf Width $(\mu \mathrm{m})$} \\
\hline Exp. & ANN & Exp. & ANN \\
1.956 & 1.937 & 318.54 & 317.79 \\
\hline
\end{tabular}




\section{CONCLUSION}

An Investigation on cutting speed and kerf width on the wire electric discharge machining of $\mathrm{H} 21$ tool steel has been carried out. The relationship between the input parameters such as pulse on time, pulse off time, current, servo gap voltage and wire tension with the output parameters is modeled through RSM and ANN modeling based on RSM CCD design of experiment. The prediction capacity of ANN model is more accurate and more generalized than quadratic RSM to reach the global optimum. Comparisons are made of the above approaches by statistical analysis and after testing their performances on 7 randomly selected test cases. The developed ANN model is suitably integrated with particle swarm optimization algorithms to optimize the process parameters. It can be used as the theoretical model for the CS, KW in the future. The good agreement between the predicted and experimentally obtained CS, KW confirms the applicability of these evolutionary computational techniques for optimization of process parameters in the WEDM process. Thus, it can also be concluded that even though RSM is most widely used method for non-traditional machining optimization, ANN-PSO hybrid methodology may present a better alternative. The optimization is used to exhibit machine product with higher quality and lower cost. The optimum combination is pulse on time $0.95 \mu \mathrm{sec}$, pulse off time $9.5 \mu \mathrm{sec}$, current $165 \mathrm{~A}$, servo gap voltage $20 \mathrm{v}$ and wire tension is $1.4 \mathrm{~kg}$. Based on the ANOVA and F-test, Pulse on-time was found to be the most significant parameter among all machining parameters. Longer pulse on-time results in higher cutting speed, and kerf width. Pulse off-time also significant on cutting speed. Current was very less effective on cutting speed and kerf width, while a major effect of servo voltage and wire tension has been found on kerf width.

\section{REFERENCES}

[1] Kumar P, Chauhan SR. Machinability Study on Finish Turning of AISI H13 Hot Working Die Tool Steel with Cubic Boron Nitride (CBN) Cutting Tool Inserts Using Response Surface Methodology (RSM). Arab J Sci Eng 2015; 40:1471-1485.

[2] Maher I, \& Sarhan AA, Hamdi M. Review of improvements in wire electrode properties for longer working time and utilization in wire EDM machining. The International Journal of Advanced Manufacturing Technology 2015; 76:329-351.

[3] Mahapatra SS, Patnaik A. Optimization of wire electrical discharge machining (WEDM) process parameters using Taguchi method. The International Journal of Advanced Manufacturing Technology 2007; 34:911-925.

[4] Patil NG, Brahmankar PK. Some studies into wire electro-discharge machining of alumina particulate-reinforced aluminum matrix composites. The International Journal of Advanced Manufacturing Technology 2010; 48:537-555.

[5] Pellicer N, Ciurana J, Delgado J. Tool electrode geometry and process parameters influence on different feature geometry and surface quality in electrical discharge machining of AISI H13 steel. Journal of Intelligent Manufacturing 2011; 22:575-584.

[6] Ramakrishnan R, Karunamoorthy L. Multi response optimization of wire EDM operations using robust design of experiments. The International Journal of Advanced Manufacturing Technology 2006; 29: 105-112.

[7] Ikram A, Mufti NA, Saleem MQ and Khan AR. Parametric optimization for surface roughness, kerf and MRR in wire electrical discharge machining (WEDM) using Taguchi design of experiment. Journal of Mechanical Science and Technology 2013 ; 27 (7):2133-2141.

[8] Saha P, Tarafdar D, Pal SK, Saha P, Srivastava AK, Das K. Multi-objective optimization in wire-electro-discharge machining of TiC reinforced composite through Neuro-Genetic technique. Applied Soft Computing 2013; 13: 2065-2074.

[9] Yang RT, Tzeng CJ, Yang YK \& Hsieh MH. Optimization of wire electrical discharge machining process parameters for cutting tungsten. The International Journal of Advanced Manufacturing Technology 2012; 60:135-147.

[10] Danial Ghodsiyeh, Abolfazl Golshan, S. Izman Multi-objective process optimization of wire electrical discharge machining based on response surface methodology. Journal of the Brazilian Society of Mechanical Sciences and Engineering. 2014; 36:301-313.

[11] Mandal D, Pal SK, Saha P. Modeling of electrical discharge machining process using back propagation neural network and multiobjective optimization using non-dominating sorting genetic algorithm-II. Journal of Materials Processing Technology 2007; 186:154162.

[12] Tosun N, Cogun C, Tosun G. A study on kerf and material removal rate in wire electrical discharge machining based on Taguchi method. Journal of Materials Processing Technology 2004; 152:316-322.

[13] Mandal N, Doloi B, Mondal B. Predictive modeling of surface roughness in high speed machining of AISI 4340 steel using yttria stabilized zirconia toughened alumina turning insert. International Journal of Refractory Metals and Hard Materials 2013; 38:40-46.

[14] Shayan, AV, Afza, RA \& Teimouri, R. Parametric study along with selection of optimal solutions in dry wire cut machining of cemented tungsten carbide (WC-Co). Journal of Manufacturing Processes 2013; 15(4): 644-658.

[15] Shiva M, Atashi H, Tabrizi FF, Mirzaei AA, Zare A. The application of hybrid DOE/ANN methodology in lumped kinetic modeling of Fischer-Tropsch reaction. Fuel processing technology 2013; 106: 631-640.

[16] Karaye D. Prediction and control of surface roughness in CNC lathe using artificial neural network. Journal of material processing technology 2009; 209: 3125-3137.

[17] Çaydaş U, Hasçalık A. A study on surface roughness in abrasive waterjet machining process using artificial neural networks and regression analysis method. Journal of materials processing technology 2008; 202(1): 574-582.

[18] Malviya R, Pratihar DK. Turning of neural networks using particle swarm optimization to model MIG welding process. Swarm and evolution computation 2011; 1: 223-235.

[19] Sathiyaa P, Aravindan S, Haq AN, Paneerselvam K. Optimization of friction welding parameters using evolutionary computational techniques. Journal of materials processing technology 2009; 209: 2576-2584.

[20] Arindam Majumder. Comparative study of three evolutionary algorithms coupled with neural network model for optimization of electric discharge machining process parameters. Proc IMechE Part B: J Engineering Manufacture. 2014; 1-13. DOI: $10.1177 / 0954405414538960$. 